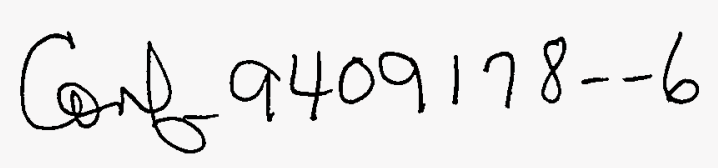

Author(s):

Submitted to:
Elimination of Solvents and Waste by Supercritical Carbon Dioxide in Precision Cleaning

Sarah B. Williams, Kenneth E. Laintz, Jerome C. Barton, and W. Dale Spall

American Chemical Society Emerging Technologies in Hazardous Waste Management VI

Altlanta, Georgia

September 19-21, 1994

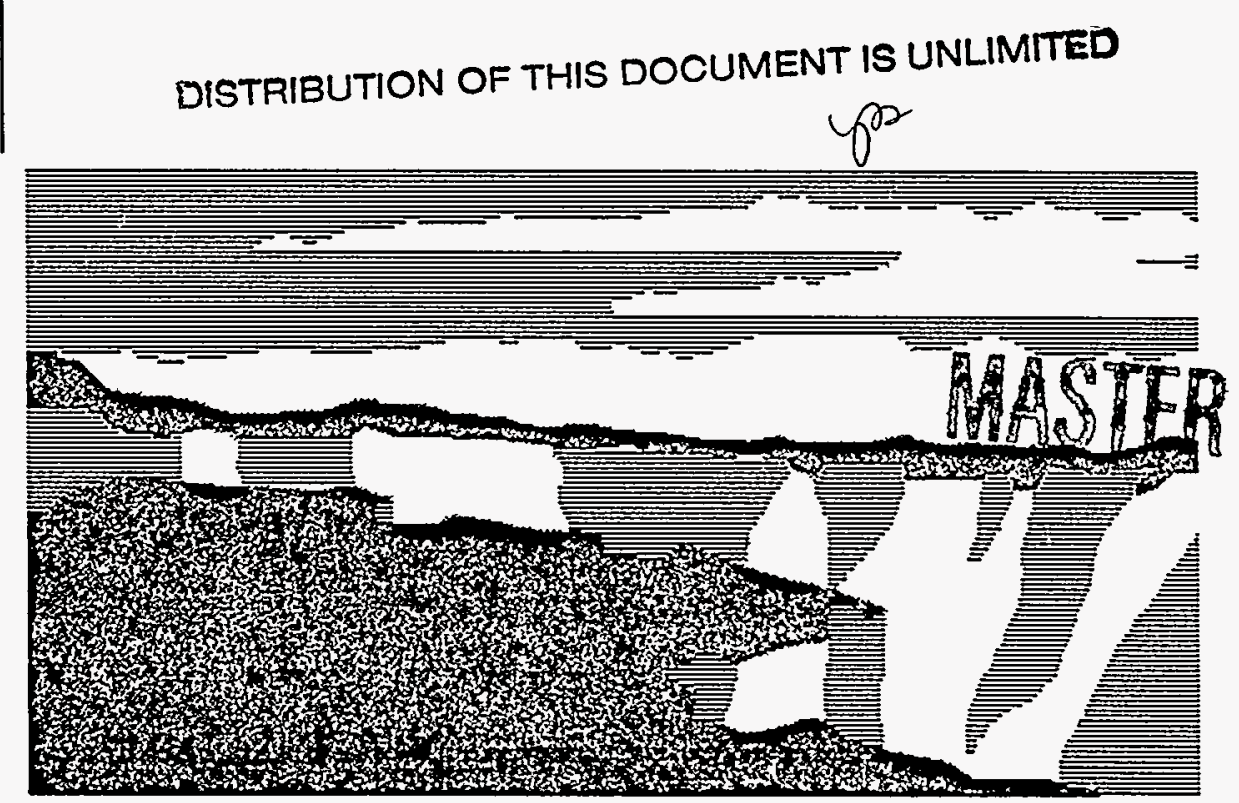

Los Alamos National Laboratory, an affirmative action/equal opportunity employer, is operated by the University of California for the US Department of Energy under contract W-7405-ENG-36. By acceptance of this article, the publisher recognizes that the US Government retains a nonexclusive, royalty-free license to publish or reproduce the published form of this contribution, or to allow others to do so, for US Government purposes. The Los Alamos National Laboratory requests that the publisher identify this artide as work performed under the auspices of the US Department of Energy. 


\section{DISCLAIMER}

This report was prepared as an account of work sponsored by an agency of the United States Government. Neither the United States Government nor any agency thereof, nor any of their employees, make any warranty, express or implied, or assumes any legal liability or responsibility for the accuracy, completeness, or usefulness of any information, apparatus, product, or process disclosed, or represents that its use would not infringe privately owned rights. Reference herein to any specific commercial product, process, or service by trade name, trademark, manufacturer, or otherwise does not necessarily constitute or imply its endorsement, recommendation, or favoring by the United States Government or any agency thereof. The views and opinions of authors expressed herein do not necessarily state or reflect those of the United States Government or any agency thereof. 


\section{DISCLAIMER}

Portions of this document may be illegible in electronic image products. Images are produced from the best available original document. 


\title{
ELIMINATION OF SOLVENTS AND WASTE BY SUPERCRITICAL CARBON DIOXIDE IN PRECISION CLEANING
}

\author{
S.B. Williams, K.E. Laintz*, J.C. Barton, and W.D. Spall \\ Los Alamos National Laboratory \\ Chemical Science and Technology Division \\ CST-12, MS E537 \\ Los Alamos, New Mexico 87545
}

\begin{abstract}
Physiochemical properties of supercritical carbon dioxide make it ideally suited for removing commonly encountered contaminants found in the precision cleaning of optical components, computer parts, and electronic assemblies. Data will be presented on a survey demonstrating the successful removal of cutting and machine oils, silicone oils, body oils and hydraulic fluids from a variety of surfaces with supercritical carbon dioxide to, at, or below precision cleaning standards (less than 10 micrograms of contaminant per square centimeter of surface). Replicate studies were performed in both a small bench-scale unit (10 milliliter cleaning vessel) and in a large-scale unit (60 liter, 14 inch diameter cleaning vessel) showing the ability to scale small experiments to commercial sizes. Applicability of this supercritical fluid cleaning technique to commercial operations was evaluated in the areas of contaminant removal efficiencies, surface interactions, operational costs, and environmental waste reduction/elimination.
\end{abstract}




\section{INTRODUCTION}

Current manufacturing processes for electronic assemblies, optical and laser components, precision mechanical, electromechanical, and computer parts often require the use of chlorofluorocarbons, or CFCs, as the solvent of choice for the removal of oil and fluid contaminations. The Montreal Protocol and the Clean Air Act amendments mandate the phaseout of ozone depleting solvents including CFCs by the end of 1995 . Therefore, alternative cleaning methods to achieve precision cleaning will be necessitated. The physiochemical properties of supercritical fluids, high diffusivities, low viscosities, low surface tension, and temperature-pressure dependence of solvent strength, make them ideally suited for the removal of many common contaminants. The combination of both gas and liquid like properties of supercritical fluids permit penetration into porous and intricate parts of assemblies and components allowing the solubilization of common contaminants followed by their subsequent removal to very low levels.

Carbon dioxide is commonly used in supercritical fluid processing and cleaning operations for several reasons. One reason $\mathrm{CO}_{2}$ is often used is because its critical parameters (critical temperature and pressure) are easily reached, resulting in low equipment and operational costs. The critical temperature occurs at a mild $31{ }^{\circ} \mathrm{C}$, and the critical pressure occurs at 1070 poundsper-square-inch (psi). Besides its ready availability, $\mathrm{CO}_{2}$ is safe to work with. It is environmentally benign and nontoxic in comparison to many commonly used organic solvents, including CFCs. The use of supercritical $\mathrm{CO}_{2}$ reduces the overall use of organic solvents in industrial processes which contributes to the reduction of hazardous. For these reasons, $\mathrm{CO}_{2}$ has been in use for many years as an extraction solvent in the food and flavor industries.

The physical states of all pure substances can be represented using a phase diagram. When discussing supercritical fluids as solvents it is often helpful to define such a fluid in terms of a temperature and pressure phase diagram as shown in Figure 1. In Figure 1 the phase diagram illustrates a substance's three physical states (solid, liquid, and gas) as a function of both temperature and pressure. The critical fluid region is characterized by a critical pressure $\left(\mathrm{P}_{c}\right)$ and 
temperature $\left(T_{c}\right)$ and can be defined as the P-T region at which the gas cannot be compressed into the liquid state upon increasing pressure. It is known that the solvent properties of supercritical $\mathrm{CO}_{2}$ are related to density. The density is controlled by manipulating the pressure and temperature of the fluid. In general, as the density of $\mathrm{CO}_{2}$ increases, the solvation power also increases, which leads to excellent solubilities for many organic compounds in the supercritical fluid phase.

The removal of organic contaminants to a level of less than 10 micrograms of contaminant per square centimeter of surface is a desired level of precision cleaning required by many manufacturers ${ }^{1}$ and has been used as a standard cleanliness level performance specification. ${ }^{2}$ Precision cleanliness is either very desirable or required for the function of parts such as electronic assemblies, optical and laser components, electromechanical elements, hydraulic items, computer parts, ceramics, plastics, and many cast or machined metals. ${ }^{1}$ However, the ultimate level of cleanliness is dictated by the planned end-use of the component. Of course, any CFC replacement solvent should be able to clean commonly encountered soils to at least $10 \mu \mathrm{g} / \mathrm{cm}^{2}$ from a variety of surfaces, including printed circuit boards, plastics, metals, rubbers, composites, and glasses. In order to determine whether this level of precision cleaning could be achieved with supercritical carbon dioxide, small bench scale (10 ml cleaning vessel) and large scale (60 L cleaning vessel) studies were undertaken. Ten organic contaminants and seven substrate materials listed in Table 1 were selected as representative of commonly encountered components found in manufacturing processes. This study was conducted as a survey to determine the general applicability of supercritical fluid cleaning technology.

\section{EXPERIMENTAL SECTION}

Small, bench scale cleaning studies were conducted as single point extraction data. These studies were conducted using a Suprex SFE/50 extraction unit (Suprex Corp., Pittsburgh, PA.) containing a $10 \mathrm{ml}$ cleaning vessel. The small scale study investigated the removal of 14 cutting oils, 17 machining oils, $\mathrm{SiO}_{\mathrm{x}}$ fluids, 5 water soluble cutting fluids, and 120 individual chemicals from 18 metals, glass, quartz, sapphire, and 24 polymers. ${ }^{3}$ However, only those studies 
duplicated by the large scale tests will be discussed here. Stainless steel 340 and 316, machined and electropolished strips, reagent grade copper, epoxy fiber filled standard PC board, borosilicate glass, and cast magnesium coupons measuring 0.5 in. $\times 2$ in. $\left(12.9 \mathrm{~cm}^{2}\right)$ were contaminated with $2 \mu \mathrm{g} / \mathrm{cm}^{2}$ of each of the substances in Table 1 .

The selection of contaminant compounds listed in Table 1 are representative of larger classes of common contaminants. For example, TRIM ${ }^{\circledR}$ SOL (Master Chemical Co., Perrysburg, OH) is a water miscible cutting fluid, Tapmatic ${ }^{\circledR}$ Cutting Fluid (LPS Laboratories, Inc., Tucker, GA) is a light machining oil, 3-IN-ONE ${ }^{\circledR}$ Oil (Boyle-Midway, Inc., New York, NY) is a light lubricating oil, SAE 30 Motor Oil (Quaker State, Oil City, PA) represents a heavy machining oil, silicone oil (Aldrich Chemical Co., Milwaukee, WI) is a high temperature lubricating oil, Triton ${ }^{\circledR}$ X-100 (Dow-Corning, Midland, MI) is a nonionic surfactant, hexadecane (EM Science, Gibbstown, NJ) is a component of kerosene and diesel, and mineral oil (Furrs Supermarket, Los Alamos, NM) and hydraulic fluid (Gold Eagle Co., Chicago, II) represent common organic contaminants found on parts and components. A surrogate mixture of skin lipids (components obtained from Aldrich) was prepared based upon previous work. ${ }^{4-6}$ This type of contamination can be found in sweat, fingerprints, and other human contamination, and is often a major constituent of organic contamination found on parts, components, and assemblies.

The contaminant materials were applied as a dilute solutions to the entire 0.5 in. by 2 in. substrate surfaces using a manual pipettor. Once the application solvent had evaporated to dryness, a contaminated substrate was placed in a $10 \mathrm{ml}$ extraction vessel and dynamically extracted (solvent flow through the cell) using $\mathrm{SFC} / \mathrm{SFE}$ grade $\mathrm{CO}_{2}$ (with siphon tube and $1500 \mathrm{psi} \mathrm{He}$ head space, Scott Specialty Gases, Inc., Longmont, CO) at $300 \mathrm{~atm}$ and $45^{\circ} \mathrm{C}$ for $15 \mathrm{~min}$. with a flow rate of $2.8 \mathrm{ml} / \mathrm{min}$. After flowing through the extraction cell, the fluid was let down directly into the inlet of an HP 5971 GCMS operated in the split mode with a split ratio of 150 to 1 . The GC column was a $60 \mathrm{~m} \times 0.25 \mathrm{~mm}$ i.d. DB-5 ( $5 \%$ crosslinked Ph-Me silicone) column programmed from 30 to $275^{\circ} \mathrm{C}$ with a temperature ramp of $7^{\circ} \mathrm{C} / \mathrm{min}$. Peak areas and subsequent concentrations of the extracted compounds were calculated from the total ion chromatograms by the HP software. The 
extractions were run in triplicate which yielded and overall $7 \%$ relative standard deviation. Data were prepared as percent of original material removed from the substrate.

For the large scale study, a SUPERSCRUB ${ }^{\mathrm{TM}} \mathrm{CO}_{2}$ cleaning system, Model No. 2, manufactured by EnviroPro Technologies ${ }^{\mathrm{TM}}$ (Erie, PA) equipped with a $60 \mathrm{~L}$ cleaning vessel was utilized. The SUPERSCRUB ${ }^{\mathrm{TM}}$, introduced in 1991, was the first large scale, computer controlled, commercially available supercritical $\mathrm{CO}_{2}$ cleaning apparatus. The cleaning conditions for all runs programmed into the SUPERSCRUB ${ }^{\mathrm{TM}}$ unit controller consisted of a $\mathrm{CO}_{2}$ (food grade, TriGas, Irving, TX) flow rate of $500 \mathrm{lb} . / \mathrm{hr}$ at $1500 \mathrm{psi}$. The $\mathrm{CO}_{2}$ was heated to $40^{\circ} \mathrm{C}$ and the chamber impeller was set at a speed of $500 \mathrm{rpm}$. This impeller mixes the $\mathrm{CO}_{2}$ within the cleaning chamber to provide improved contaminant solvation and removal. Complete operational specifications and details for the SUPERSCRUB ${ }^{\mathrm{TM}}$ can be found elsewhere. ${ }^{7}$

The large scale supercritical $\mathrm{CO}_{2}$ cleaning study also investigated the removal of the contaminant compounds listed in Table 1 from similar substrates. In this case 314 stainless steel was used. The epoxy board was rigid-flex, multilayer through-hole-mount board which provided a very porous surface unlike the smooth glass fiber filled epoxy board used in the small scale study. The six substrate materials used in the large scale study, aluminum, brass, copper, epoxy, glass, and 314 stainless steel, were cut into 2 in. $\times 2$ in. $\left(51.63 \mathrm{~cm}^{2}\right)$ coupons and placed in a slotted stainless steel box. This box contained six rows and twenty-five slots per row and held the coupons in a fixed position while in the cleaning chamber. The coupon holder was milled to allow $\mathrm{CO}_{2}$ to flow around the coupons and through the box. The contaminant compounds listed in Table 1 were applied as dilute solutions in HPLC grade Freon 113 (1,1,2-trichlorotrifluoroethane, J.T. Baker, Phillipsburg, NJ) to the entire surfaces of duplicate substrates using a manual pipettor at $500 \mu \mathrm{g}$ and $2500 \mu \mathrm{g}$ contamination levels for total contaminations of about $10 \mu \mathrm{g} / \mathrm{cm}^{2}$ and $50 \mu \mathrm{g} / \mathrm{cm}^{2}$. While it can be argued that a contamination level of $10 \mu \mathrm{g} / \mathrm{cm}^{2}$ already passes precision cleaning specifications $^{2}$, a residue is usually still visible at this level. Since the final determination of cleanliness is often visual observation, removing contaminants to cleanliness levels below 10 $\mu \mathrm{g} / \mathrm{cm}^{2}$ is desirable. After the solvent had evaporated, the box containing 24 randomly placed 
contaminated coupons and 6 blank coupons was placed within the SUPERSCRUB ${ }^{\mathrm{TM}}$ cleaning vessel and the extraction carried out. At the end of the cleaning run, the box was removed from the cleaning vessel and an analytical wash was performed on each of the thirty coupons to determine the amount of contaminant remaining. The analytical was performed by placing the coupons into a $100 \mathrm{~mm}$ dia. petri dish containing $10 \mathrm{ml}$ of Freon 113 . The petri dish was placed into a dry sonication bath for one minute. The remaining Freon 113 was transferred to a $5 \mathrm{ml}$ volumetric flask and brought to volume. The coupons were washed with Freon 113 into a $3 \mathrm{ml}$ Infrasil quartz cuvette with a $1 \mathrm{~cm}$ pathlength. The cuvette was placed into a Buck Total Hydrocarbon Analyzer Model 404 (Buck Scientific Inc., East Norwalk, CT) and the concentration determined by comparison of the hydrocarbon absorption at a fixed wavelength of $2924 \mathrm{~cm}^{-1}(3.42 \mu \mathrm{m})$ to standard solutions. Standard calibration curves were linear with an $r^{2}$ of at least 0.99 . The average mass detection limit for this procedure was about $8 \mu \mathrm{g}$, which corresponds to 0.15 $\mu \mathrm{g} / \mathrm{cm}^{2}$ for the $51.6 \mathrm{~cm}^{2}$ substrate coupons. Although, the detection limit for silicone oil with this method was about $107 \mu \mathrm{g}\left(2 \mu \mathrm{g} / \mathrm{cm}^{2}\right)$, it is below the desired precision cleaning level. The overall procedure was shown to have an average RSD of $2.9 \%$ and performed in duplicate for a total of four trials for each substrate.

\section{RESULTS AND DISCUSSIONS}

Large scale cleaning or extraction systems using supercritical fluids like the SUPERSCRUB ${ }^{\mathrm{TM}}$ are conceptually simple, and a basic schematic diagram of such a system is illustrated in Figure 2. The component operation can be understood when a cleaning cycle is superimposed over a P-T phase diagram as shown in Figure 3 to explain the overall operation of the system. Initially, a source of $\mathrm{CO}_{2}$ such as a liquid storage vessel or standard gas cylinders as shown in figure 2 provides liquid at a $\mathrm{P} 1-\mathrm{T} 1$ to some type of pump. The pump in figure 2 compresses the $\mathrm{CO}_{2}$ above its critical pressure to P2-T1. This liquid can then be introduced into the extraction vessel of figure 2 at P2-T1 and then heated above the critical temperature to P2-T2 or heated to P2-T2 prior to introduction to the extraction vessel. The items are cleaned by continuous displacement of the vessel's volume for some fixed period of time at P2-T2. This type of cleaning mode is referred to as dynamic cleaning. The addition of a static cleaning mode, often a better method for 
substances with low solubilities, does not continuously flow fresh solvent through the extraction chamber. Removal of the dissolved contaminants from the supercritical $\mathrm{CO}_{2}$ is achieved by decompressing the carbon dioxide to $\mathrm{P} 1-\mathrm{T} 2$ within the separator shown in figure 2. As the $\mathrm{CO}_{2}$ enters the gas phase at P1-T2, the dissolved contaminants precipitate from the gas and are separated from the system. The gaseous $\mathrm{CO}_{2}$ is cooled in figure 2 to the liquid state at P1-T1 and is passed back into the flow stream to be used again in the cleaning process. The items that were in the chamber are removed, clean and dry, ready for immediate use.

Overall operational costs for $\mathrm{CO}_{2}$ cleaning tend to be lower than for other cleaning processes when the entire cleaning process is considered. ${ }^{8}$ The low critical parameters of $\mathrm{CO}_{2}$ make it quite cost efficient in terms of energy use during operation. It was found that energy costs for our large scale cleaning operation for a standard run at a temperature of $30^{\circ} \mathrm{C}$ and a pressure of $1500 \mathrm{psi}$ cost about $\$ 0.90$ per hour while the highest energy costs occurred at $40^{\circ} \mathrm{C}$ and 3500 psi for a total electrical cost of about $\$ 2.75$ per hour. ${ }^{9}$ Even though energy consumption costs are low, the pressures required to attain a supercritical phase can cause the cost of the cleaning vessel to be relatively high. This initial perceived high capital cost of supercritical $\mathrm{CO}_{2}$ cleaning equipment ${ }^{8}$ has probably caused many potential users to opt for aqueous type cleaning systems. Currently, however, more companies are offering supercritical $\mathrm{CO}_{2}$ cleaning systems and custom tailoring these systems to process needs. These efforts have driven the capital costs of $\mathrm{CO}_{2}$ cleaning systems down. Meanwhile, other operational costs for $\mathrm{CO}_{2}$ cleaning systems have always been low. For example, the price of liquid $\mathrm{CO}_{2}$ is about $\$ 0.05$ per pound, while Freon 113 costs around $\$ 45.00$ per pound, offsetting much of the potentially high initial costs. In consideration of these factors, supercritical $\mathrm{CO}_{2}$ cleaning is a viable alternative for many cleaning applications.

Results for the small scale removal of machining oils and fluids from the substrates listed in Table 1 are summarized in Table 2. In general, the removal rates for these fluids from all of the surfaces listed were near quantitative as seen from the table. In particular, supercritical $\mathrm{CO}_{2}$ was quite effective in the removal of the various oils and fluids from all metal surfaces, removing, for example, from about 86 to $99 \%$ of the $3-\mathrm{IN}-\mathrm{ONE}^{\circledast}$ Oil. It should be pointed out that with a $7 \%$ RSD, there is no statistical difference between an $86 \%$ removal rate and a $99 \%$ removal rate at 
the $5 \%$ level using a standard two-tailed mean comparison $t$-test with 4 degrees of freedom. The removal rates listed for cast magnesium in Table 2 are not quantitative. Cleaning from cast or porous materials has the potential to be quantitative using more rigorous conditions such as a longer extraction time or the use of a static extraction step (substrate immersed in supercritical $\mathrm{CO}_{2}$ with no flow through the cell) followed by a dynamic extraction, and indeed, further testing showed this to be true. Silicone oil was also not as efficiently removed as the other contaminants from the substrates investigated. This may be due to solubility or to fractionation of the oil with the higher less soluble components remaining on the surface.

The removal of skin lipids, Triton ${ }^{\circledast} \mathrm{X}-100$, and hexadecane is summarized in Table 3. While it was no surprise that these lipophilic organic compounds were quantitatively removed, of particular importance is the quantitative removal of skin lipids. Again, however, using the test conditions as described, cast magnesium showed lower extraction efficiencies. For example, cast magnesium had a fingerprint removal rate of $56 \%$, while stainless steel 316 had a removal rate of $95 \%$. The low removal rate from the cast magnesium sample is again believed to be due to the porosity of the substrate surface. Longer extraction times (30-45 $\mathrm{min}$ ), however, resulted in quantitative removal of the skin lipids from the magnesium surface.

In general, the results of the contaminant removal studies using the SUPERSCRUB ${ }^{\mathrm{TM}}$ closely correlate with those observed in the small scale study. The overall results for the removal of machining oils and fluids at the two different contamination levels investigated in the large scale study are summarized in Table 4. As seen from the table, most of the machining oils and fluids, 3-IN-ONE ${ }^{\circledast}$ oil, Tapmatic ${ }^{\circledR}$ cutting fluid, SAE 30 motor oil, hydraulic jack oil, and mineral oil, were effectively removed from all substrates at both contamination levels below the precision cleaning level. On the other hand, at a contamination level of $50 \mu \mathrm{g} / \mathrm{cm}^{2}, \mathrm{TRIM}^{\otimes} \mathrm{SOL}$ and silicone oil were not removed from most of the substrates to a precision clean level below 10 $\mu \mathrm{g} / \mathrm{cm}^{2}$. In fact, there was visible silicone oil contamination remaining on the $50 \mu \mathrm{g} / \mathrm{cm}^{2}$ contaminated coupons after the SUPERSCRUB ${ }^{\mathrm{TM}}$ run. An exception in this case was the removal of $\mathrm{TRIM}^{\otimes}$ SOL from copper, where $83 \%$ of the initial $50 \mu \mathrm{g} / \mathrm{cm}^{2}$ was removed. It is likely that 
those contaminants not efficiently removed at $1500 \mathrm{psi}$ and $40^{\circ} \mathrm{C}$ would be removed at higher pressures and temperatures corresponding to increased solvation capacity of the supercritical $\mathrm{CO}_{2}$.

In general, removal rates for the coupons contaminated at the $50 \mu \mathrm{g} / \mathrm{cm}^{2}$ were higher than those of the coupons contaminated at $10 \mu \mathrm{g} / \mathrm{cm}^{2}$. An example of this is shown in Figure 4 with the removal of TRIM ${ }^{\circledast}$ SOL from the metal substrates cleaned using the SUPERSCRUB ${ }^{\mathrm{TM}}$. As shown in the figure, the removal of TRIM ${ }^{\circledR} \mathrm{SOL}$ is appreciably higher from the metal coupons contaminated at $50 \mu \mathrm{g} / \mathrm{cm}^{2}$ as compared to those contaminated at $10 \mu \mathrm{g} / \mathrm{cm}^{2}$. It has been shown that the solubility of components within a mixture often have higher solubilities in supercritical $\mathrm{CO}_{2}$ than the pure components themselves. ${ }^{10}$ This phenomenon is caused by one or more components acting as solubility enhancers for other components. With more contaminant present at $50 \mu \mathrm{g} / \mathrm{cm}^{2}$, it is possible that the overall solubilities of the contaminants were increased to yield higher extraction efficiencies. In fact, metal coupons were placed in the SUPERSCRUB ${ }^{\mathrm{TM}}$ for cleaning that had been saturated with $3-\mathrm{IN}_{-} \mathrm{ONE}^{\circledR}$ oil to the point where oil was dripping from the coupons. Following cleaning with $\mathrm{CO}_{2}$ at $1500 \mathrm{psi}$ and $40^{\circ} \mathrm{C}$, the oil was removed down below the precision clean level. It should be noted that these results in suggest that $\mathrm{CO}_{2}$ may be used as a one step bulk cleaning method in addition to its use in precision cleaning.

The removal of skin lipids, Triton ${ }^{\otimes} \mathrm{X}-100$, and hexadecane in the large scale SUPERSCRUB ${ }^{\mathrm{TM}}$ study also correlate well to those results obtained in the small scale study, and these results are summarized in Table 5. As in the small scale study, these organic contaminants were quantitatively removed from all substrates at both contamination levels including the porous rigidflex, through-hole epoxy board. While the removal of these contaminants was well below the precision clean level of $10 \mu \mathrm{g} / \mathrm{cm}^{2}$, the skin lipids left a visible film on the $50 \mu \mathrm{g} / \mathrm{cm}^{2}$ contaminated coupons after the SUPERSCRUB ${ }^{\mathrm{TM}}$ run. This film may represent a small residual of the lower solubility components in the skin lipids mixture. Again, longer extraction times would probably remove this residual film. 
Overall, the removed contaminants showed no evidence of redeposition on the blank coupons randomly placed throughout the stainless steel holder. Additionally, the coupon substrate did not effect the removal of the contaminants by supercritical carbon dioxide, except in the case of rigidflex, through-hole epoxy board which demonstrated consistently lower rates of removal due to its surface topography, analogous to the cast magnesium used in the small scale study. The large errors associated with the large scale SUPERSCRUB ${ }^{\mathrm{TM}}$ experiments are largely due to the spread of data obtained with the rigid-flex, through-hole epoxy board. However, all raw data were used to calculate the removal rates and only four data points were collected, contributing to the large RSD. In some cases, results were sporadic. For example, a $50 \mu \mathrm{g} / \mathrm{cm}^{2}$ deposited contaminant might have been removed to below the analytical detection limit one run while the duplicate run yielded a removal rate around $10 \mu \mathrm{g} / \mathrm{cm}^{2}$. A more thorough investigation is currently being conducted to determine the cause of the spurious data.

It should be noted that the removal of the all of the contaminants was independent of the placement of the coupons inside of the stainless steel holder in the SUPERSCRUB ${ }^{\mathrm{TM}}$. Overall results have shown that the removal of organic residues with supercritical $\mathrm{CO}_{2}$ is quite effective, however, it is important to compare $\mathrm{CO}_{2}$ cleaning with a typical degreasing technique. While the above study was conducted as a survey to determine the general applicability of this technique, actual operating conditions need to be examined for the implementation of supercritical $\mathrm{CO}_{2}$ cleaning in an actual process. Basically, the density of the $\mathrm{CO}_{2}$ cleaning solvent needs to be adjusted to achieve the appropriate level of cleanliness desired. In this case, the removal of a typical drawing oil from a stainless steel surface using supercritical $\mathrm{CO}_{2}$ was compared with a standard Freon 113 wash. After the drawing oil had been applied to the stainless steel surface in a uniform coating, the surface was cleaned using both supercritical $\mathrm{CO}_{2}$ at different densities and using a Freon 113 wash. After cleaning with supercritical $\mathrm{CO}_{2}$, the stainless steel surface was washed with Freon 113 to determine the amount of oil remaining. As before, all Freon 113 washes were monitored with the Buck IR total hydrocarbon analyzer to measure the amount of drawing oil in the wash solution. The overall results of this study are shown in Figure 5. As seen from the figure in this case, the cleaning efficiency of supercritical $\mathrm{CO}_{2}$ is equivalent to that obtained using a Freon 113 wash when the density reaches about $0.5 \mathrm{~g} / \mathrm{ml}$. As the density of the 
supercritical $\mathrm{CO}_{2}$ is increased, the cleaning efficiency also increases to a level better than that obtained using Freon 113. This investigation illustrates the selective solvation capability of a supercritical fluid based on temperature and pressure and demonstrates the need for careful preliminary studies to determine appropriate operating conditions. As a result, a supercritical fluid has a unique advantage in that it has the potential to selectively remove one contaminant from a surface while leaving a desired coating intact.

\section{CONCLUSION}

Cleaning with supercritical fluids is not an absolute or drop-in solution to all cleaning problems. It is best for parts that are incompatible with water or are thermally sensitive. Supercritical $\mathrm{CO}_{2}$ has been shown and is noted for its solvation of organic compounds having mid-to-low volatilities, and these types of compounds are common contaminants requiring removal to precision clean levels. On the other hand, inorganic or ionic contaminants are insoluble in supercritical fluids with low polarities such as carbon dioxide, and alternate cleaning methods should be considered for the removal of these types of contaminants. To a first approximation, cleaning with supercritical $\mathrm{CO}_{2}$ appears to be contaminant dependent while being surface independent. The use of supercritical $\mathrm{CO}_{2}$ as a cleaning solvent can reduce the need for washing in organic solvents, thus reducing their overall use in manufacturing processes. This in turn reduces hazardous waste by minimizing the solvent required to dispose of collected contaminants. Furthermore, cleaning with supercritical $\mathrm{CO}_{2}$ removes the need for energy consuming drying steps which increases the speed of the overall cleaning process since less inventory needs to be held in the cleaning and drying phases of manufacturing. Therefore, along with the effectiveness of cleaning with $\mathrm{CO}_{2}$, the economics of the entire cleaning process may direct the use of $\mathrm{CO}_{2}$ in cleaning applications other than precision cleaning. These studies demonstrate that waste reduction and elimination of hazardous solvents utilizing supercritical carbon dioxide at relatively low temperatures and pressures during the manufacturing processes is a viable process. 


\section{ACKNOWLEDGMENT}

This work was performed under funding from the Industrial Waste Program Office, Department of Energy, Office of Industrial Technologies. 


\section{REFERENCES}

1. Spall, W.D. International Journal of Environmentally Conscious Design \& Manufacturing, 1993, 2(1), pp. 81-86.

2. American National Standards Institute, ANSI/IPC-CH-65, 1990, 7.2.3, pp. 47-48.

3. Unpublished results, currently in preparation for publication.

4. Downing, D.T., Strauss, J.S., and Pochi, P.E., Journal of Investigative Dermatology, 1969, 53(5), pp. 322-327.

5. Downing, D.T. and Strauss, J.S., Journal of Investigative Dermatology, 1974, 62(3), pp. 228-244.

6. Strauss, J.S., Pochi, P.E., and Downing, D.T., Journal of Investigative Dermatology, 1976, 67(1), pp. 90-97.

7. EnviroPro Technologies, 2930 W. 22nd St., Erie, PA 16512, (814) 838-5888.

8. Snowden-Swan, L.J. PNL-10044/UC-602, 1994, Pacific Northwest Laboratory, Richland, Washington.

9. Barton, J. LA-12786, 1994, Los Alamos National Laboratory, Los Alamos, New Mexico.

10. Kurnik, R.T. and Reid, R.C., Fluid Phase Equilibrium, 1982, 8, p. 93. 
Table 1. Contaminants cleaned from substrate materials using supercritical $\mathrm{CO}_{2}$ in large and small scale cleaning studies.

\begin{tabular}{|c|c|c|}
\hline \multicolumn{2}{|c|}{ Contaminants } & Substrate Materials \\
\hline Triton $^{\circledast} \mathrm{X}-100$ & Skin Lipid Mixture: & Aluminum \\
\hline Hexadecane (C16) & $30 \%$ Triolein & Borosilicate glass \\
\hline $3-\mathbb{N}-\mathrm{ONE}^{\circledR}$ Oil & $25 \%$ Oleic acid & Copper \\
\hline Tapmatic $^{\otimes}$ Cutting Fluid & $25 \%$ Cotyl palmitate & Brass \\
\hline SAE 30 Motor Oil & $15 \%$ Squalene & ${ }^{\dagger}$ Glass fiber filled epoxy board \\
\hline Silicone Oil & 2.5\% Cholesterol & ${ }^{\dagger}$ Cast magnesium \\
\hline TRIM $^{\otimes}$ SOL & $2.5 \%$ Cholesterol oleate & ${ }^{\dagger} 340$ Stainless steel \\
\hline Mineral Oil & & $\dagger_{316 \text { Stainless steel }}$ \\
\hline${ }^{\ddagger}$ Hydraulic Jack Oil & & $\ddagger_{314}$ Stainless steel \\
\hline & & ${ }^{\dagger}$ Rigid-flex, through-hole epoxy boarc \\
\hline
\end{tabular}

${ }^{\dagger}$ Substrates used in small scale study only

${ }^{\ddagger}$ Substrates and compounds used in large scale study only 
Table 2. Small scale supercritical $\mathrm{CO}_{2}$ machining oils and fluids removal results.

\begin{tabular}{|l|c|c|c|c|c|c|}
\hline \multirow{3}{*}{ Substrate Materials } & \multicolumn{6}{|c|}{ Contaminant Compounds (Percent Removal ${ }^{*}$ ) } \\
\cline { 2 - 7 } & $\begin{array}{c}\text { 3-IN-ONE } \\
\text { Oil }\end{array}$ & TRIM $^{\otimes}$ SOL & $\begin{array}{c}\text { Tapmatic } \\
\text { Cutting Fluid }\end{array}$ & $\begin{array}{c}\text { SAE 30W } \\
\text { Motor Oil }\end{array}$ & Silicone Oil & Mineral Oil \\
\hline \hline Stainless Steel 340 & 98 & 94 & 95 & 91 & 88 & 98 \\
Stainless Steel 316 & 96 & 90 & 94 & 92 & 84 & 94 \\
Copper & 96 & 85 & 96 & 91 & 79 & 93 \\
Aluminum & 86 & 83 & 97 & 94 & 85 & 87 \\
Brass & 99 & 85 & 89 & 95 & 89 & 89 \\
Cast Magnesium & 75 & 72 & 99 & 80 & 71 & 70 \\
Glass & 89 & 84 & 98 & 91 & 85 & 88 \\
Epoxy board & 93 & 82 & 98 & 94 & 83 & 89 \\
\hline
\end{tabular}

${ }^{*}$ Based on triplicate runs with an average $7 \% \mathrm{RSD}$ 
Table 3. Small scale supercritical $\mathrm{CO}_{2}$ removal of skin lipids, Triton ${ }^{\otimes} \mathrm{X}-100$, and hexadecane.

\begin{tabular}{|l|ccc|}
\hline \multirow{2}{*}{ Substrate Materials } & \multicolumn{3}{|c|}{ Contaminant Compounds (Percent Removal ${ }^{*}$ ) } \\
\cline { 2 - 4 } & Skin Lipids & Triton $^{\circledR}$ X-100 & Hexadecane \\
\hline \hline Stainless Steel 340 & 94 & 98 & 91 \\
Stainless Steel 316 & 95 & 97 & 90 \\
Copper & 95 & 93 & 92 \\
Aluminum & 94 & 93 & 95 \\
Brass & 94 & 98 & 98 \\
Cast Magnesium & 56 & 78 & 85 \\
Glass & 94 & 95 & 98 \\
Epoxy board & 96 & 94 & 96 \\
\hline
\end{tabular}

*Based on triplicate runs with an average 7\% RSD 
Table 4. Results of large scale supercritical $\mathrm{CO}_{2}$ machining oils and fluids removal study at contamination levels of $10 \mu \mathrm{g} / \mathrm{cm}^{2}$ and 50 $\mu \mathrm{g} / \mathrm{cm}^{2}$.

\begin{tabular}{|c|c|c|c|c|c|c|c|}
\hline \multirow[b]{2}{*}{ Substrate Materials } & \multicolumn{7}{|c|}{ Contaminant Compounds (Percent Removal ${ }^{*}$ ) } \\
\hline & 3-IN-ONE ${ }^{\circledR}$ & TRIM $^{\circledast}$ SOL & Tapmatic $^{(8)}$ & SAE 30W & Silicone Oil & Hydraulic Oil & Mineral Oil \\
\hline \multicolumn{8}{|l|}{ Brass } \\
\hline $10 \mu \mathrm{g} / \mathrm{cm}^{2}$ & $>99$ & 64 & 95 & 92 & 54 & 45 & $>99$ \\
\hline $50 \mu \mathrm{g} / \mathrm{cm}^{2}$ & $>99$ & 72 & 99 & 95 & 75 & 89 & $>99$ \\
\hline \multicolumn{8}{|l|}{ Stainless Steel 314} \\
\hline $10 \mu \mathrm{g} / \mathrm{cm}^{2}$ & $>99$ & 42 & 89 & 78 & 65 & 90 & $>99$ \\
\hline $50 \mu \mathrm{g} / \mathrm{cm}^{2}$ & $>99$ & 77 & 98 & 88 & 72 & 98 & $>99$ \\
\hline \multicolumn{8}{|l|}{ Glass } \\
\hline $10 \mu \mathrm{g} / \mathrm{cm}^{2}$ & 98 & 27 & 94 & 87 & 60 & 85 & 98 \\
\hline $50 \mu \mathrm{g} / \mathrm{cm}^{2}$ & $>99$ & 76 & 98 & 94 & 74 & 96 & $>99$ \\
\hline \multicolumn{8}{|l|}{ Aluminum } \\
\hline $10 \mu \mathrm{g} / \mathrm{cm}^{2}$ & 97 & 52 & 96 & 95 & 58 & 83 & 97 \\
\hline $50 \mu \mathrm{g} / \mathrm{cm}^{2}$ & 99 & 66 & 99 & 96 & 73 & 96 & 99 \\
\hline \multicolumn{8}{|l|}{ Copper } \\
\hline $10 \mu \mathrm{g} / \mathrm{cm}^{2}$ & 99 & 20 & 54 & 93 & 55 & 43 & 99 \\
\hline $50 \mu \mathrm{g} / \mathrm{cm}^{2}$ & $>99$ & 83 & 99 & 95 & 58 & 89 & $>99$ \\
\hline \multicolumn{8}{|c|}{ Rigid-flex Epoxy Board } \\
\hline $10 \mu \mathrm{g} / \mathrm{cm}^{2}$ & 94 & & 65 & 61 & $<1$ & $<1$ & 94 \\
\hline $50 \mu \mathrm{g} / \mathrm{cm}^{2}$ & 94 & & 96 & 84 & 70 & 93 & 94 \\
\hline
\end{tabular}

*Based on averages of four runs with an average $50 \%$ RSD 
Table 5. Large scale supercritical $\mathrm{CO}_{2}$ removal of skin lipids, Triton ${ }^{\circledR} \mathrm{X}-100$, and hexadecane at contamination levels of $10 \mu \mathrm{g} / \mathrm{cm}^{2}$ and $50 \mu \mathrm{g} / \mathrm{cm}^{2}$.

\begin{tabular}{|c|c|c|c|}
\hline \multirow[b]{2}{*}{ Substrate Materials } & \multicolumn{3}{|c|}{ Contaminant Compounds (Percent Removal*) } \\
\hline & Skin Lipids & Triton $^{\otimes} \mathrm{X}-100$ & Hexadecane \\
\hline \multicolumn{4}{|l|}{ Brass } \\
\hline $10 \mu \mathrm{g} / \mathrm{cm}^{2}$ & 99 & $>99$ & 92 \\
\hline $50 \mu \mathrm{g} / \mathrm{cm}^{2}$ & 89 & $>99$ & 99 \\
\hline \multicolumn{4}{|l|}{ Stainless Steel 314} \\
\hline $10 \mu \mathrm{g} / \mathrm{cm}^{2}$ & $>99$ & $>99$ & 96 \\
\hline $50 \mu \mathrm{g} / \mathrm{cm}^{2}$ & $>99$ & $>99$ & 99 \\
\hline \multicolumn{4}{|l|}{ Glass } \\
\hline $10 \mu \mathrm{g} / \mathrm{cm}^{2}$ & $>99$ & 99 & 96 \\
\hline $50 \mu \mathrm{g} / \mathrm{cm}^{2}$ & 99 & 97 & 99 \\
\hline \multicolumn{4}{|l|}{ Aluminum } \\
\hline $10 \mu \mathrm{g} / \mathrm{cm}^{2}$ & 98 & 97 & 96 \\
\hline $50 \mu \mathrm{g} / \mathrm{cm}^{2}$ & $>99$ & $>99$ & 99 \\
\hline \multicolumn{4}{|l|}{ Copper } \\
\hline $10 \mu \mathrm{g} / \mathrm{cm}^{2}$ & 97 & 99 & 91 \\
\hline $50 \mu \mathrm{g} / \mathrm{cm}^{2}$ & 97 & $>99$ & 99 \\
\hline \multicolumn{4}{|c|}{ Rigid-flex Epoxy Board } \\
\hline $10 \mu \mathrm{g} / \mathrm{cm}^{2}$ & 77 & 94 & 84 \\
\hline $50 \mu \mathrm{g} / \mathrm{cm}^{2}$ & 92 & 93 & 94 \\
\hline
\end{tabular}

*Based on averages of four runs with an average $60 \% \mathrm{RSD}$ 


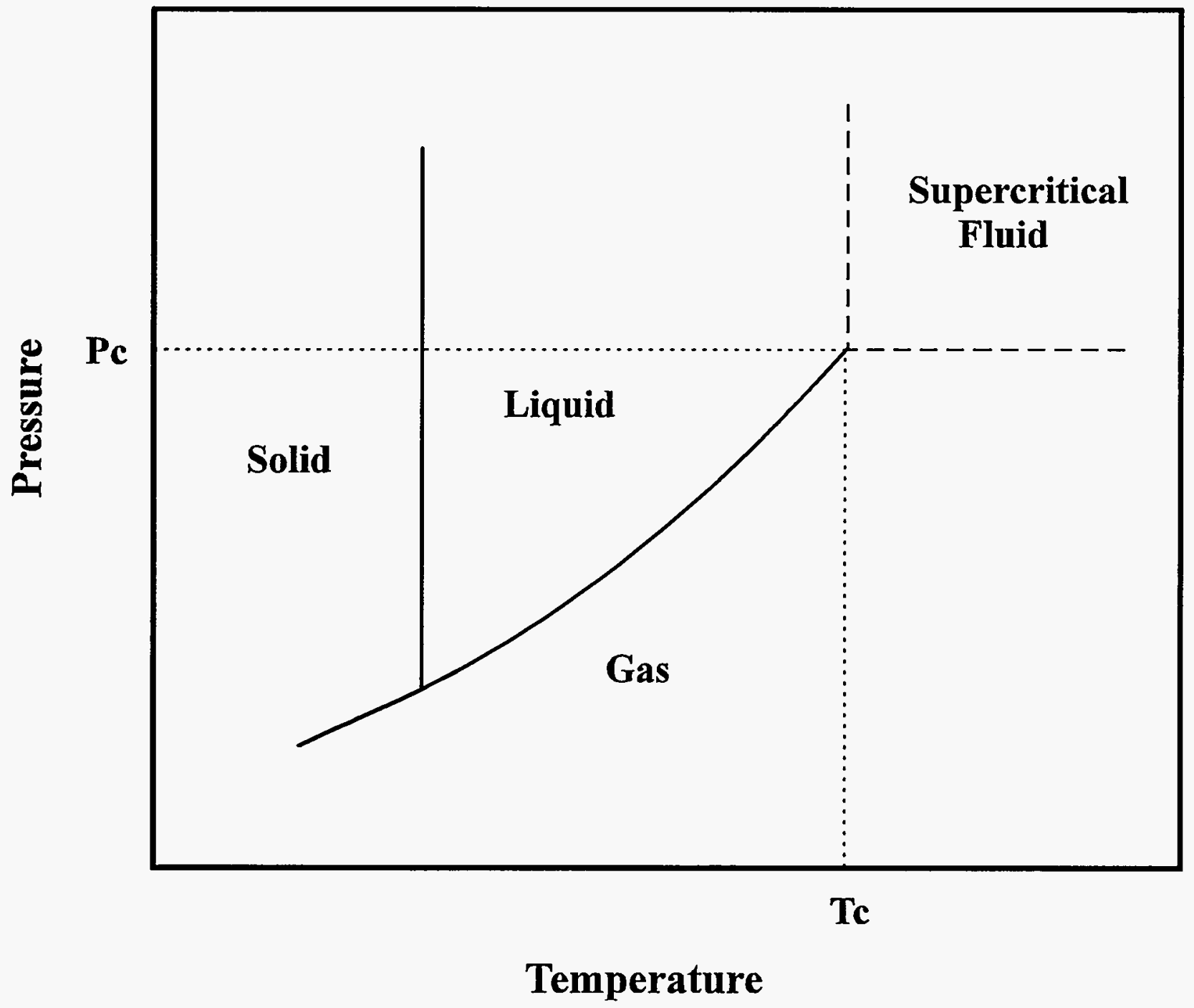

Figure 1. Generic pressure-temperature phase diagram of a pure compond. 


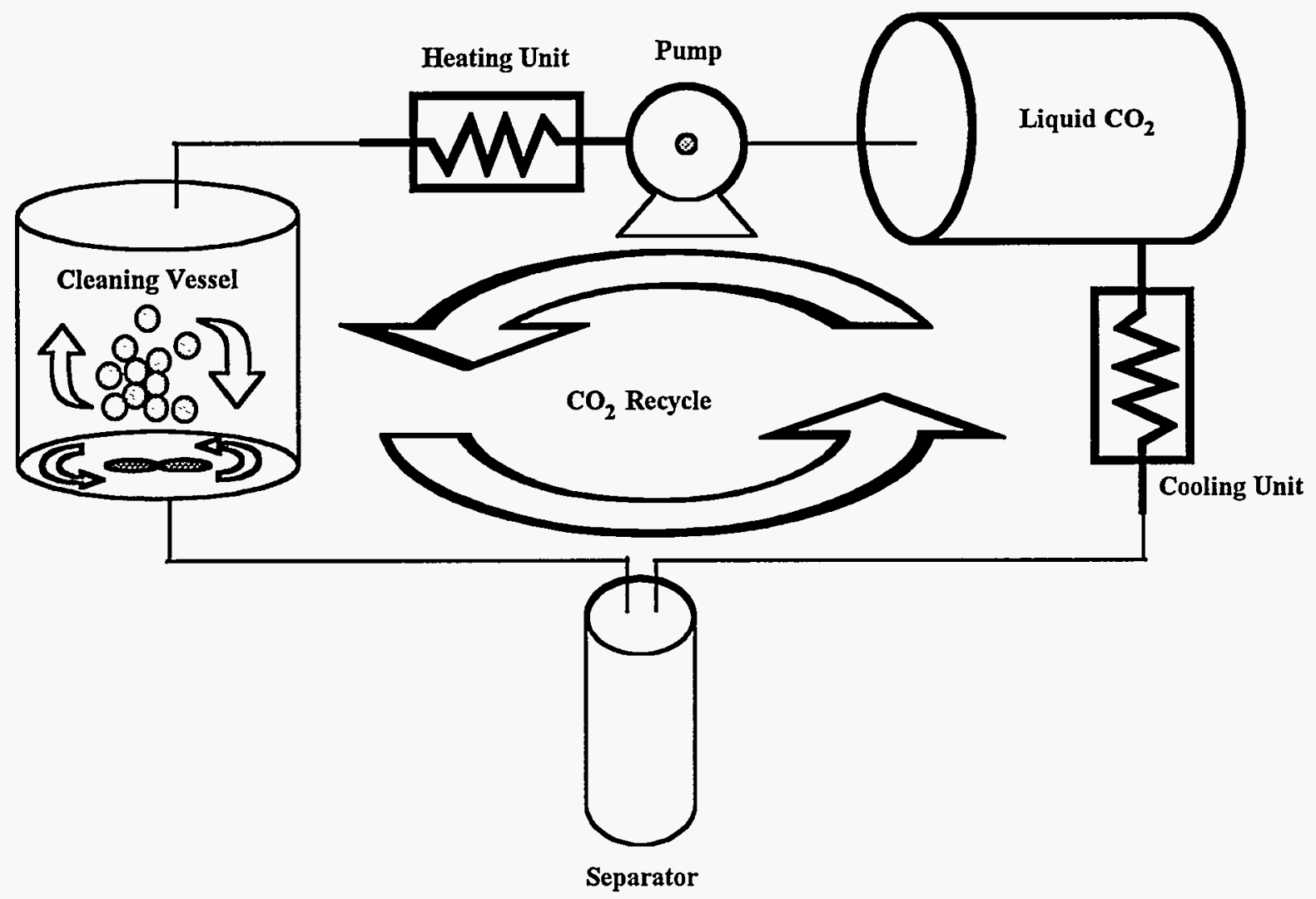

Figure 2. Basic schematic diagram of a $\mathrm{CO}_{2}$ cleaning system. 


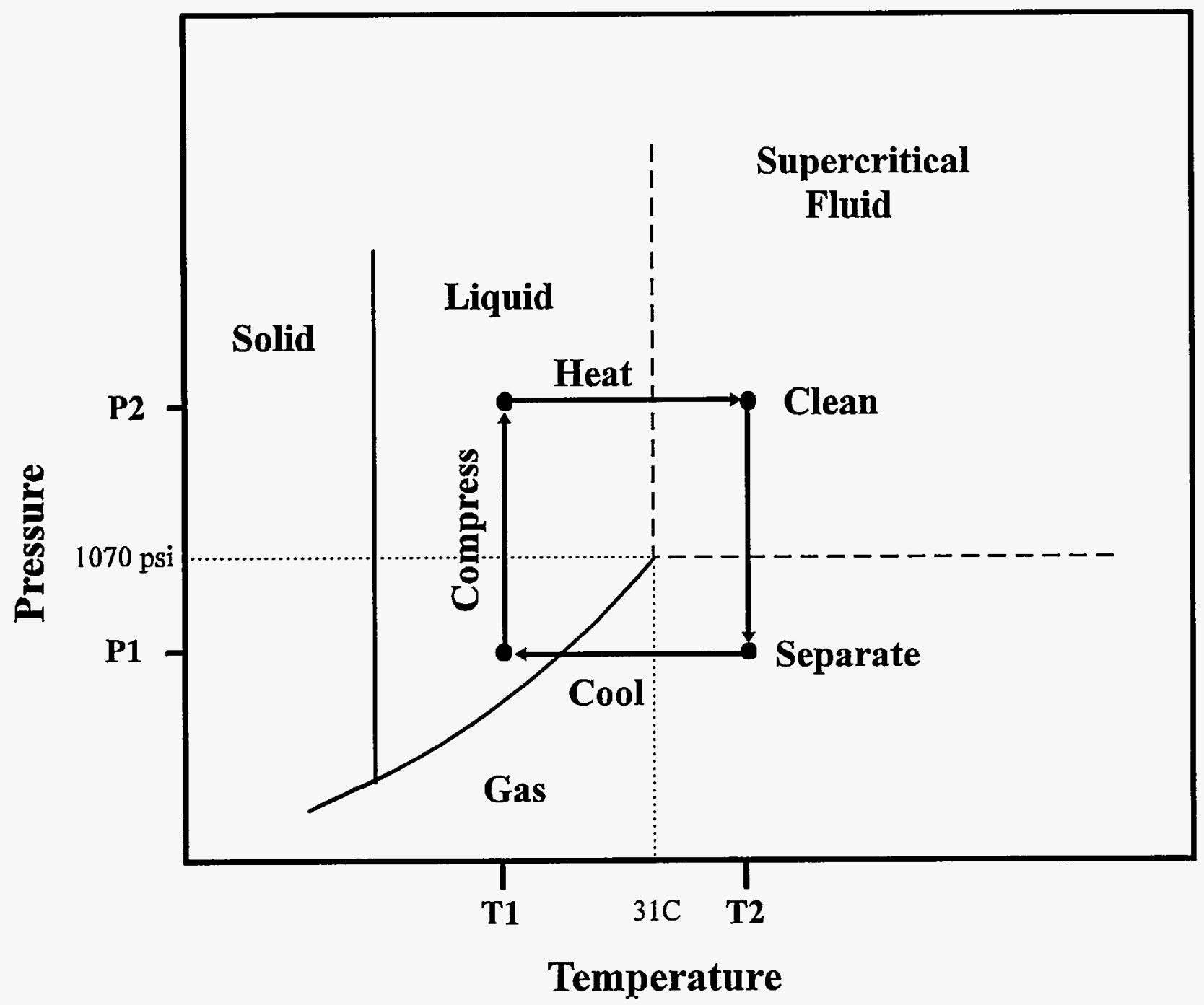

Figure 3. Phase behavior of $\mathrm{CO}_{2}$ in cleaning cycle. 


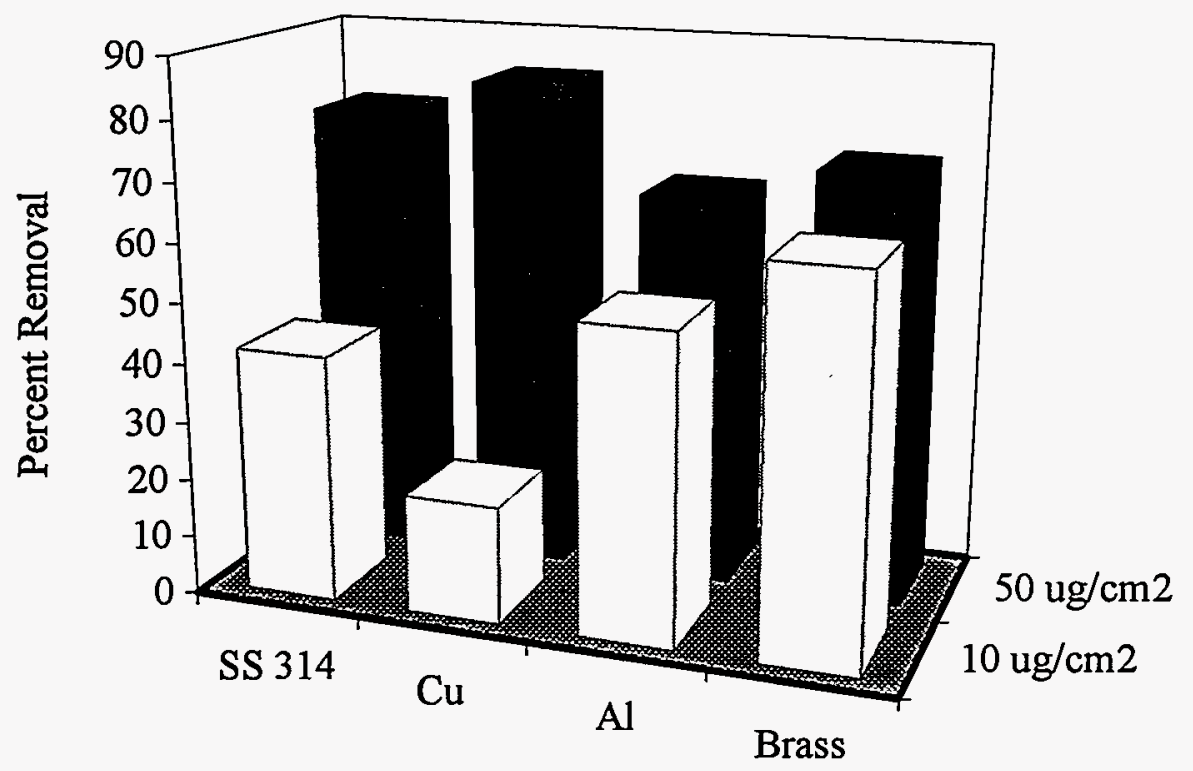

TRIM SOL Contaminated Metals

Figure 4. Comparison of the cleaning efficiency of supercritical $\mathrm{CO}_{2}$ for the removal of TRIM ${ }^{\circledR}$ SOL from metal surfaces contaminated at 10 and $50 \mu \mathrm{g} / \mathrm{cm}^{2}$. 


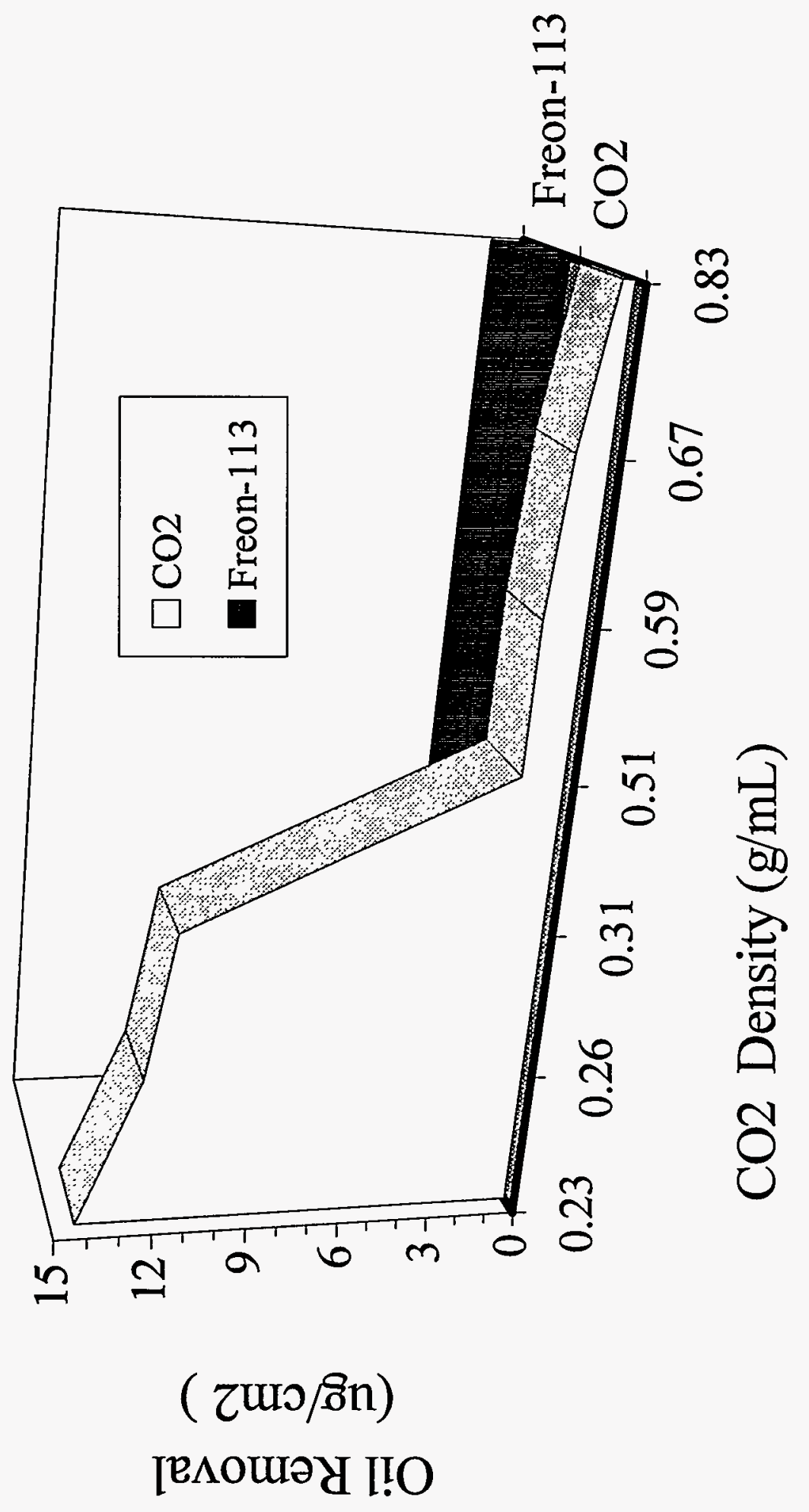

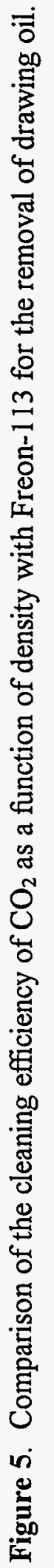

